\title{
Os desafios para a formação de alunos leitores: a análise de uma experiência na escola
}

\section{The challenges for the formation of students readers: the analysis of an experience at school}

https://doi.org/10.34112/2317-0972a2018v36n73p155-171

João Marcos Pulz Araújo ${ }^{1}$

Elvira Cristina Martins Tassoni²

RESUMO: Este artigo apresenta os resultados de estudo de caso que teve o objetivo de analisar uma experiência em uma escola pública de cidade do interior do estado de São Paulo, denominada Projeto Sarau Literário, visando a desenvolver nos alunos o gosto pela leitura literária. O Projeto propõe diversas atividades, envolvendo o universo literário, que colaboram para aproximar os alunos de novas expressões culturais e estéticas relacionadas com a literatura. Pautados pela teoria histórico-cultural, identificamos, no projeto, fatores que contribuem ou dificultam a aproximação dos alunos da literatura e da leitura literária. Nesse recorte, destacamos a mediação pedagógica e as mudanças no comportamento de leitor dos alunos. Os resultados contribuem para as reflexões sobre a qualidade e a natureza da mediação e sua relação com a formação de leitores. Também evidenciaram que o Projeto Sarau Literário constitui proposta promissora para a formação de alunos leitores.

PALAVRAS-CHAVE: Literatura; leitura literária; mediação pedagógica.

ABSTRACT: This paper shows the results of a case study that aimed at analysing an experience in a public school in the State of São Paulo that was called "Projeto Sarau Literário" targeting at developing good feelings, among students, for literary reading. The project

1. Pontifícia Universidade Católica de Campinas, Campinas, SP, Brasil.

2. Pontifícia Universidade Católica de Campinas, Campinas, SP, Brasil. 
proposed many activities involving the literary universe that collaborated to bring students closer to new cultural and aesthetic expressions related to literature. Based on a historical-cultural theory, we have identified, in the projetc, factors that contribute or hinder the students' approach to literature and literary reading. In this sense, we highlight the pedagogical mediation and the changes in students' reading behavior. The result contributes for the reflections about the quality and the constitution of mediations and its relation with reader development. We have evidence that the "Projeto Sarau Literário" constitutes a promising proposal for reading development.

KEYWORDS: Literature; literary reading; pedagogical mediation.

\section{INTRODUÇÃO}

A leitura estabelece uma relação entre leitor e conteúdo e, por isso, torna-se importante no processo de constituição humana. Tem potencial para fornecer determinada bagagem cultural que poderá ser percebida como positiva ou não pelo leitor, dependendo da sua própria perspectiva em relação a esse conteúdo.

Assim, consideramos que o incentivo à leitura literária é um grande desafio que não pode ser responsabilidade apenas da escola, ainda que esta desempenhe um papel fundamental.É uma responsabilidade também da família e de toda a sociedade. Souza (2011, p. 221) assume que

[...] a prática da leitura vai além de uma simples ferramenta técnica ou uma habilidade mecânica de decodificação e produção de sinais gráficos. Ela é, também, uma prática social que propicia ao indivíduo o aumento de sua bagagem cultural - pela leitura podemos conhecer, imaginar, criar e dialogar com novos olhares e ideias que, aos poucos, transformam nossa maneira de entender e questionar a realidade.

Buscamos, portanto, refletir sobre a literatura como elemento significativo para o desenvolvimento de crianças e adolescentes, assim como o papel que a escola pode assumir, como mediadora nesse processo, ao despertar nos alunos as potencialidades decorrentes do investimento em atividades relacionadas com a literatura. Consideramos importante socializar iniciativas que valorizem a leitura literária, especialmente nas atividades acadêmicas escolares.

É nessa perspectiva que investigamos um projeto pedagógico implementado por uma escola pública estadual de um município do interior do estado de São 
Paulo. Denominado Sarau Literário, a partir da proposição de uma série de atividades ligadas ao universo literário, como teatro, contação de histórias, literatura de cordel, teatro de fantoches, entre outros, tem o objetivo de desenvolver nos alunos o gosto pela leitura literária.

O projeto foi criado em 2011 por iniciativa de uma professora de Artes. Durante a realização desta pesquisa em 2016, estava em sua sexta edição. A dinâmica de organização do Sarau Literário, desta edição estudada, definiu que os alunos dos $6^{\text {os }} 7^{\text {os }}$ anos do ensino fundamental eram os responsáveis por criar todas as apresentações para o público, constituído pelos alunos dos $2^{\text {os }}$ aos $5^{\text {os }}$ anos, também do ensino fundamental.

O objetivo desta pesquisa foi investigar o Projeto Sarau Literário, identificando os fatores que contribuem ou dificultam a formação de alunos leitores.

\section{LEITURA LITERÁRIA: DESAFIOS E POSSIBILIDADES}

Compreendemos a literatura como uma construção simbólica que envolve um conjunto de valores, experiências e conhecimentos que são concebidos a partir de um determinado contexto histórico e cultural - o mundo em que vivemos. Desse modo, o leitor vai sendo transformado pelas suas leituras e segue revelando, de maneira muito evidente, o recorte de uma época. Brito (2012, p. 28) destaca que:

Conceituar e determinar a natureza e a estrutura do fenômeno literário é sempre questão de indagação dos teóricos desde Aristóteles até os dias atuais, haja vista que as relações entre arte real e homem se modificam e se alteram constantemente, em decorrência dos valores culturais, ou seja, a Literatura é um dado de cultura e, desse modo, a ideia que se faz dela é sempre medida a partir de conteúdos fornecidos pelo contexto histórico-cultural de cada época.

O conceito que temos de literatura está relacionado aos valores culturais dos quais nos apropriamos e que nos são fornecidos pelo ambiente em que construímos nossas relações sociais. Magnani (2001, p. 07) enfatiza que "[...] o termo literário designa algo vivo e dinâmico, em constante transformação; é um fato social [...]”. Se a literatura como fato social transforma-se, ela também transforma aqueles que estão envolvidos com suas práticas. 
Chartier (2011, p. 20) afirma que “[...] cada leitor, a partir de suas próprias experiências, individuais ou sociais, históricas ou existenciais, dá um sentido mais ou menos singular, mais ou menos partilhado, aos textos de que se apropria”. Este conceito de apropriação do texto é relevante para compreendermos a literatura como possibilidade de promoção da transformação do sujeito leitor. Ou seja, ao se apropriar daquele conteúdo literário, o leitor subverte-o e ressignifica-o de acordo com sua própria visão de mundo. Trata-se de uma visão que faculta à literatura um significado relevante na medida em que oferece subsídios, no plano imaginário, para a construção da própria história. Ela seria mais do que apenas um adereço cultural carregado de contornos simbólicos, tratando-se de importante elemento de formação social. Conforme destaca Rocco (1992, p. 03):

Em todos os tempos e entre todos os povos que a produziram, a literatura sempre representou a expressão mais complexa e elaborada de um espaço cultural. Nela encontramos universos, antes opostos e polarizados, então plasmados, através do simbolismo mágico da linguagem verbal.

A literatura, na perspectiva de Rocco, é a expressão heterogênea da cultura de um povo. Ela manifesta, de maneira singular e utilizando os códigos semióticos, todo um contexto que revela quem é esse povo, quais os seus valores, qual a sua história. Nesse sentido, tanto a literatura como a leitura constituem-se potentes fenômenos de transformação.

Especificamente no que se refere à leitura, Silva (2005, p. 13) a define “[...] como prática humana dialógica que produz significados e, ao produzi-los, possibilita transformações nos indivíduos". Da mesma forma, Magnani (2001, p. 49) reitera que a leitura "[...] implica não só a decodificação de sinais, mas também a compreensão do signo linguístico enquanto fenômeno social". Evidencia ainda que "tratar de leitura e literatura é tratar de um fenômeno social” (MAGNANI, 2001, p. 43). Segundo Soares (2016), quanto mais os indivíduos tiverem acesso às práticas sociais de leitura e de escrita, tanto mais complexa se torna, para eles, a compreensão do mundo ao redor.

Quanto à escola, a imersão no universo literário passa impreterivelmente por outras demandas que estão além apenas da abstração estética, um dos mais relevantes conceitos quando se trata de leitura literária. O ensino de literatura (na escola) está condicionado a valores e compromissos que muitas vezes mais afastam do que aproximam os alunos da leitura literária. De acordo com Leahy-Dios (2004, p. XXV): 
Há determinados pressupostos comumente associados ao processo de ensinar e aprender literatura. Como disciplina, literatura é parte de uma agenda educacional determinada por compromissos ideológicos, papéis e expectativas político-culturais.

É preciso considerar a perspectiva apontada por Leahy-Dios ao analisarmos a questão da formação do leitor na escola, agência que tem um papel muito importante em tal processo. Como se dá o acesso aos livros - em especial nas escolas públicas - e quais são as experiências propostas para que os alunos se sintam envolvidos pela leitura literária? Se observarmos a perspectiva do livro como um subproduto da indústria cultural, fica clara a percepção de que se trata de um artigo caro para muitas pessoas, o que acaba por se somar como mais um elemento a desestimular seu consumo.

Desse modo, acreditamos que projetos como o Sarau Literário podem constituir importantes experiências de fomento de discussões sobre livros (clássicos, atuais, best-sellers), de incentivo à leitura e à escrita literária e, também, de meio para intensificar os investimentos em ampliação de acervos literários nas escolas. Para além disso, a experiência literária tem sua importante relevância na ampliação do contexto histórico-cultural de uma época. A literatura como elemento de formação social amplia conhecimentos, valores e experiências, trazendo complexidade para as formas de compreender o mundo à nossa volta e, assim, promove transformações naqueles que com ela se envolvem.

Entretanto, na escola, o ensino da literatura parece vincular-se a mecanismos de controle por meio de cobranças, imposições e avaliações. Muitas vezes vem marcado mais por informações normativas e menos formativas.

Partindo do pressuposto de que um dos principais papéis da educação literária como disciplina de estudos é a representação cultural de sociedades, é preciso observar que ela se submete a imposições verticais, tais como programas e requisitos de avaliação. (LEAHY-DIOS, 2004, p. 10).

É relevante observarmos que na escola existe uma configuração historicamente constituída de controle vertical. Trata-se de uma estrutura vinculada a um projeto de sociedade que pode não só desestimular o interesse dos alunos pela leitura literária, como também pode não avaliar de forma qualificada os resultados da apropriação literária.

Na perspectiva de Vygotski (1989) o desenvolvimento do indivíduo é resultado de um processo histórico-cultural em que ele transforma e é transformado pelas 
relações sociais nas interações com outros indivíduos. E é por intermédio dessas interações que ele internaliza as formas culturalmente estabelecidas, num processo dialético de construção da subjetividade, e que envolve para além das informações, as experiências relacionadas à literatura.

Quando os alunos participam do Projeto, envolvendo-se, ensaiando, realizando as atividades de maneira diligente, podem ressignificar os conceitos relativos não somente ao universo literário, mas, também, sobre os professores, os colegas e a escola, configurando-se em um processo que vai marcar suas relações humanas, transformando-as. Tosta (2012, p. 64) aponta que "[...] a teoria histórico-cultural enfatiza a importância da escolarização como um local privilegiado, capaz de promover mudanças qualitativas nos processos de pensamento dos indivíduos". Certamente a escola é um local privilegiado devido à possibilidade de acesso a uma quantidade grande de relações sociais e outras contingências culturais, que podem auxiliar nos processos de desenvolvimento dos alunos. O Projeto Sarau Literário, sob a perspectiva histórico-cultural, se configura como instrumento que oportuniza aos alunos a aproximação de novos códigos culturais contribuindo para o seu desenvolvimento.

Considerando que as experiências dos alunos no Projeto são mediadas (pelos professores, pelos outros colegas, pelas obras lidas e ouvidas, pelas imagens e por outros elementos simbólicos do contexto), destacamos a relação da mediação com outro conceito de Vygotski (1989, p. 97) - zona de desenvolvimento proximal - que se refere a funções em "estado embrionário", ou seja, processos em desenvolvimento. $\mathrm{O}$ autor define zona de desenvolvimento proximal como:

[...] a distância entre o nível de desenvolvimento real, que se costuma determinar através da solução independente de problemas, e o nível de desenvolvimento potencial, determinado através da solução de problemas sob a orientação de um adulto ou e colaboração com companheiros mais capazes.

Para Vygotski (1989, p. 102), “[...] cada assunto tratado na escola tem a sua própria relação específica com o curso do desenvolvimento da criança, relação essa que varia à medida que a criança vai de um estágio para outro".

Importante compreendermos o conceito de Vygotski nesse processo de aprendizado numa perspectiva que envolve a atividade mediada. No momento em que os alunos se desenvolvem, novos assuntos podem ser abordados. No caso da pesquisa em questão, poderíamos afirmar que novas formas de aproximá-los da literatura/leitura 
literária podem se apresentar. Dessa forma, aquilo que o aluno fazia com a ajuda/ incentivo/mediação do professor, passa a fazer sozinho, incluindo as leituras literárias.

Magnani (2001, p. 142) faz uma convocação que pode ser interpretada como um grito de socorro em favor daqueles a quem ela denomina como "exilados da palavra":

[...] se nós, professores, acreditamos na força trans-formadora da leitura da literatura, não podemos nos omitir enquanto cidadãos e educadores. Não podemos abdicar do papel histórico que nos cabe: de nos formarmos como leitores para interferir criticamente na formação qualitativa do gosto estético de outros leitores. (grifos da autora).

A autora sinaliza para a condição de participação dos professores na formação de leitores. Denota responsabilidade e compromisso com as futuras gerações, na medida em que o professor tem a condição de interferir na formação qualitativa dos leitores, colaborando para formar uma geração mais crítica e participativa, que pode significar a transformação da sociedade.

E é nesse contexto de mediação que as dimensões afetivas podem ser observadas como importantes aportes para a formação de leitores. Clot (2016, p. 93) afirma que "[...] pelo afeto, a atividade aumenta ou diminui, muda o rumo da atividade". Assim, para o autor, “[...] o afeto é a passagem de um nível de atividade a um outro, ou seja, há aqui também o desenvolvimento da intensidade da atividade. $\mathrm{O}$ afeto é, portanto, o que permite uma mudança de vitalidade (CLOT, 2016, p. 91-92).

Baseando-nos nessa mesma obra, consideramos que a afetividade atua na potência de agir, incidindo diretamente na atividade humana. Pudemos constatar, em nossas observações de campo, que as professoras afetavam os alunos potencializando a ação dos mesmos, contribuindo para a aproximação entre alunos e literatura.

\section{OBSERVAÇÕES SOBRE O PROJETO}

A pesquisa é um estudo de caso em que foram analisados os seguintes instrumentos: observação das atividades desenvolvidas antes (ensaios, preparativos, montagens de cenários e decoração) e durante a realização do Projeto Sarau Literário; entrevistas (gravadas em áudio) com a professora idealizadora do projeto e com outros professores participantes, além da equipe gestora e também com dois alunos participantes do Sarau Literário; questionário para os alunos participantes do projeto; análise de documentos com informações sobre as edições anteriores do Projeto Sarau Literário. 
As observações envolveram os seguintes aspectos: trabalhos desenvolvidos em sala de aula referentes às apresentações para o projeto; ensaios e preparativos relativos ao evento; participação dos alunos durante o Sarau Literário e seus procedimentos com relação às instruções recebidas.

As observações foram essenciais para compreendermos o funcionamento do projeto e verificar o nível de participação e envolvimento de professores e alunos. Antes da realização do Sarau Literário, acompanhamos algumas aulas de preparação para o evento com a professora de Artes, Priscila $^{3}$, sua organizadora desde o início, e também com a professora de Língua Portuguesa, Fabíola. Observamos todo o trabalho de preparação e também os ensaios das atividades que seriam apresentadas.

As entrevistas nos permitiram aprofundar as informações, assim como conhecer seus impactos na formação de dois alunos, de maneira especial.

O questionário nos possibilitou obter informações dos alunos participantes na edição de 2016, buscando divisar opiniões e conceitos que melhor revelassem suas opiniões em relação à literatura e à leitura literária. Reunimos informações de 101 alunos dos $6^{\text {os }} \mathrm{e} 7^{\text {os }}$ anos do ensino fundamental (turmas que participaram dessa ação em 2016). Para evitar incompreensões e problemas de interpretação, bem como uma significativa diminuição da representatividade da amostra, aplicamos o questionário na escola, acompanhados por outros professores e por integrantes da equipe gestora.

O locus de investigação, a escola pública estadual já citada, oferece os ensinos fundamental I, fundamental II e ensino médio, contabilizando um total de 784 alunos. Conta ainda com cerca de 40 professores, duas coordenadoras pedagógicas, a diretora, dois funcionários administrativos, três da limpeza e quatro terceirizados.

\section{Resultados}

Desde o início da pesquisa pudemos observar os desafios para a viabilização e implementação do Projeto Sarau Literário. É possível transformar o comportamento de leitor dos alunos? É esse o resultado esperado pela professora Priscila, especialmente se as mudanças representarem a aproximação entre os alunos e os recursos estéticos expressos na literatura, resultando no gosto e no prazer pela leitura literária.

A partir de uma perspectiva que abrange preferências e potencialidades de cada aluno, foram propostas atividades envolvendo diferentes experiências estéticas

3. Todos os nomes aqui citados são fictícios para preservarmos a identidade dos participantes. 
relacionadas com a literatura, além de outras possibilidades como jogos de tabuleiro, oficina de origami ou gincana literária - atividades que promoveram uma atmosfera de ludicidade ao evento.

Compreendemos que o trabalho do professor, nesse processo de formação do aluno leitor, exige um repertório de habilidades que vão além de apenas indicar um bom livro ou exigir determinada leitura. Nessa direção, a mediação se revela aspecto fundamental para a formação do leitor literário, mas, igualmente, o prazer estético e também a fruição são elementos significativos e não podem ser desassociados. Sob essa perspectiva, uma das formas de afetar os alunos em relação ao universo literário é a contação de histórias, característica marcante na professora Priscila. O relato de um episódio ocorrido com uma turma do $6^{\circ}$ ano retrata bem essa peculiaridade. Ela começou a contar uma fábula que possuía alguns traços de terror, suspense, elementos que, segundo a professora, conseguem prender a atenção dos alunos, sendo um dos gêneros mais apreciados. Ela iniciou a história e, de repente, em um momento de tensão, com os alunos fixados em sua narrativa e curiosos com a continuação do relato, a professora disse que, infelizmente, não poderia continuar.

Pessoal, eu não posso. É algo terrível demais, vocês não vão conseguir suportar. Se eu continuar, vai começar a escorrer sangue do livro (Profa. Priscila).

A reação da classe foi um alvoroço quase incontrolável. Ela disse que se eles quisessem conhecer a continuação da história, saber mais, descobrir o que iria acontecer no final, teriam que pegar o livro na biblioteca. Durante o intervalo, a biblioteca foi tomada pelos alunos que comentaram com outros colegas de outras turmas. A notícia correu pela escola e até alunos do ensino médio ficaram curiosos e queriam pegar o livro para saber o que, afinal, era tão terrível assim.

É certo que tal prática isolada não mantém o seu efeito indefinidamente. Mas diferentes formas de mediar a relação dos alunos com as obras e a leitura associadas, promovem um envolvimento mais duradouro dos alunos com a literatura. Outro exemplo que apresentamos é da professora Fabíola, que incentiva os alunos a escolherem livros ou mesmo contos curtos, sem determinar a obra. Cada um escolhe o que quiser, mas todos devem socializar a história com a classe.

Essa semana mesmo eu fui com os alunos do $9^{\circ}$ ano, aí eles retiraram livros, eles têm um bimestre pra ler, daí eu agendo para o final do bimestre uma atividade, faço uma 
dinâmica do giz, se derrubar o giz perde ponto. É uma atmosfera para eles se envolverem. Caiu em você, você vem na frente da sala e pega uma pergunta dentro de uma 'caixinha misteriosa' com várias perguntas. A partir daquela pergunta você fala sobre o seu livro. É uma forma de compartilhar as leituras e de eles terem acesso a livros.

Para aqueles que não gostam eu falo: pega pelo menos um conto. Só um, pra não ficar sem nota. (Profa. Fabíola).

Os dados nos permitem afirmar que a prática da leitura literária pelos alunos não se dá de maneira mecânica, involuntária. Implica investimento de tempo e dedicação de mediadores que são importantes referências para conduzir as práticas pedagógicas. Segundo Tassoni e Leite (2011, p. 86):

A ação do professor, na constituição da relação entre o aluno e o conhecimento, demonstra a relação entre aprender e motivar-se. Da mesma forma, os significados e sentidos atribuídos pelos alunos para as ações dos professores revelam uma atitude afetiva em relação ao conhecimento - levam-nos a gostar de escrever, gostar da matemática ou de um conteúdo específico dela e ainda ampliam a visão do aluno para além de uma única situação.

A professora Priscila percebe nos alunos o despertar do gosto pela literatura, mas acrescenta que não é algo do dia para a noite. É um processo que leva muito tempo e dedicação para que os frutos comecem a surgir. A coordenadora Jéssica reforça essa tese ao comentar sobre uma prática que observou evoluir no decorrer dos anos.

Antigamente os alunos terminavam uma prova e um ou dois pegavam um livro para ler. Com o passar dos anos isso foi aumentando. Hoje a gente passa nas classes e mais da metade exercita essa prática. Isso aconteceu no decorrer desse percurso de Sarau Literário. (Coord. Jéssica).

A professora Priscila complementa essa observação, afirmando que sempre incentivou os alunos a ocuparem o tempo livre, após as provas, com leitura. E confirma essa declaração da coordenadora sobre a evolução do número de leitores com o passar dos anos, constatação que a faz se referir ao Projeto Sarau Literário como uma atividade que colaborou para essa aproximação dos alunos com a leitura literária. 
As informações obtidas pelo questionário evidenciam tais mudanças. Propusemos duas questões fechadas relativas ao Sarau Literário, com possibilidade de justificativa aberta. A primeira delas foi: Você acha que o Projeto Sarau Literário ajudou você a desenvolver o hábito de leitura? $70 \%$ dos respondentes afirmaram "sim", os outros $30 \%$ assinalaram "não". Entre os $70 \%$ que se manifestaram positivamente ao Sarau Literário como uma experiência que contribui para o desenvolvimento do hábito de leitura, 61 alunos justificaram as suas respostas destacando que o projeto motivou a busca por outras leituras e outros livros, evidenciando um interesse para além das necessidades que o próprio evento demandava (18 alunos); outros apontaram uma motivação para a leitura vinculada às demandas específicas do Sarau Literário, em relação aos livros, roteiros de teatro, poemas e filmes que estavam compondo o evento (12 alunos); outra justificativa recaiu na preocupação com os ouvintes das histórias e poemas lidos - era preciso ler bem e ainda incentivar as crianças para a leitura (21 alunos); parte dos alunos destacou a importância do projeto para mudanças pontuais em suas aprendizagens - melhoria na própria leitura, na atenção e na ampliação do vocabulário, entendendo melhor a linguagem do livro (oito alunos). Apenas dois alunos justificaram a importância do Projeto Sarau Literário para a nota.

Outra questão do questionário foi: Você gosta do Sarau Literário? A maioria dos respondentes (88\%) afirmou gostar. Destes $88 \%, 83$ alunos responderam a questão aberta - Por quê? Parte das justificativas envolveu explicações sobre as diferentes oportunidades para aprender coisas novas ( 42 alunos); outra parte relacionou-se à ajuda que davam para as crianças menores envolverem-se com as práticas de leitura (27 alunos); e por fim, outras respostas evidenciaram que gostavam do projeto porque motivava a leitura e possibilitava o aperfeiçoamento da mesma (11 alunos - dentre eles dois também destacaram, além do aperfeiçoamento da leitura, a ajuda às crianças). Cinco alunos mencionaram gostar do Sarau Literário porque é um dia que não tem aula.

Isso nos indica que o Projeto tem sido uma experiência que, ao aproximar os alunos de uma diversidade de obras do universo literário, além de possibilitar o envolvimento com distintas atividades não convencionais, pode ser percebido como uma experiência importante e que fortalece ainda mais essa apreciação. Consideramos que se trata de uma questão subjetiva, contudo pode revelar o início da formação pelo gosto da leitura literária.

$\mathrm{Na}$ entrevista que fizemos com dois alunos participantes do Sarau Literário, Kleiton e Vilson, pudemos constatar as alterações apresentadas em sua conduta 
escolar e que também revelaram, de maneira muito singular, as mudanças no comportamento de leitor proporcionadas pelo projeto.

A escolha desses alunos em particular deveu-se ao fato de terem sido mencionados pela professora Priscila como "alunos-problema". Kleiton acumulava casos recorrentes de indisciplina dentro e fora da sala de aula, o que ocasionou a sua suspensão escolar em vários momentos. A professora citou alguns episódios em que a guarda escolar teve que ser acionada para escoltar o aluno até a sua casa, pois havia a ameaça de violência física externada por outros colegas.

Entretanto, a professora Priscila, a partir das experiências e convívio com esse aluno em sala de aula, percebeu que ele poderia se sair bem na atividade de teatro, dada a sua grande habilidade criativa nas brincadeiras que fazia e também na maneira descontraída e desinibida com que sempre se manifestava na classe. A professora buscou alterar a condição marginalizada do aluno em questão, devido ao seu histórico, identificando suas potencialidades e envolvendo-o em uma proposta bem delimitada - encenar o poeta Manoel de Barros, escritor homenageado no Sarau Literário. A questão da formação do leitor, neste caso, não se sobrepôs à relevância de se trabalhar com um aluno "difícil", ainda que a leitura tenha sido recurso importante para compor o personagem.

Em nossas observações de campo pudemos confirmar a dedicação do aluno, sua conduta responsável, assim como a sujeição às instruções da professora e o seu entusiasmo tanto nos ensaios como nas apresentações.

Em suas palavras ele confirma aquilo que já havia sido relatado, tanto pela professora Priscila como por outros professores e componentes da gestão:

Eu brigava bastante, tinha péssimas notas, estava na diretoria todo dia, suspensão direto, minha mãe não sabia mais o que fazer, eu só aprontava. (Kleiton).

O ponto de partida para a sua mudança de comportamento se deu justamente com o incentivo da professora Priscila para que ele se dedicasse ao teatro. Concomitantemente ficou sabendo de um grupo de teatro organizado pela prefeitura municipal formado por alunos de escolas públicas. Convenceu a sua mãe a fazer a inscrição para entrar no grupo, participou de uma audição e foi aprovado. Mas a condição para a permanência no grupo teatral é a apresentação do boletim a cada semestre. Faltas e notas baixas são elementos que podem inviabilizar a participação. 
Dessa vez eu participei fazendo o Manoel de Barros (Sarau de 2016). Foi daí que eu percebi que é isso que eu quero. Entrei num grupo de teatro e esse grupo requer as minhas notas na escola para poder participar. Preciso levar o boletim, senão eu não posso participar de peça nenhuma.

O Sarau fez com que eu me interessasse pelo teatro. Inclusive agora a gente está vendo aqui na escola se a gente pode apresentar uma peça aqui. Eu estou participando de várias peças, porque agora eu tô conseguindo notas boas, não venho mais para a diretoria. (Kleiton).

Claramente o desafio em participar de algo que havia despertado enorme interesse influenciou as mudanças em Kleiton. Ele que era displicente, indisciplinado, desinteressado por qualquer envolvimento com o ambiente pedagógico. Ao se envolver com o teatro, por meio de ações mediadoras de Priscila, aproximou-se de obras literárias, desenvolveu maior fluência na leitura e maior habilidade na realização de pesquisas. $O$ teatro tornou-se a base para uma nova caminhada. $O$ teatro transformou-se no incentivo que ele precisava para a leitura e a leitura na ferramenta que ele precisa no teatro - uma relação dialética.

Até o ano retrasado eu lia muito mal, de pulinho em pulinho. Pra conseguir fazer o teatro tive que ler bastante. Antes não tinha nenhum livro, não gostava, minha mãe comprava eu jogava fora. Agora tenho mais de vinte na minha cômoda.

Eu leio bastante para conseguir ter uma leitura perfeita, pra conseguir participar do teatro. Como eu poderia estar no teatro hoje se não conseguisse acompanhar as leituras? Você tá no ensaio, daí tem o diálogo e você tem que dar aquela olhadinha rápida no texto. Então a leitura é uma coisa que ajudou muito.

Se eu não tivesse feito o Sarau Literário nem estaria no teatro, nem tiraria notas boas, nem teria passado de ano. (Kleiton).

O caso do aluno Kleiton torna-se emblemático, tanto pelas evidências da alteração em sua conduta em sala de aula, confirmadas pela professora Priscila, quanto pelo seu reconhecimento referente a essa mudança, e também pela consequência final, a mudança em seu comportamento de leitor. 
Outra informação que reforça a constatação de que o Projeto Sarau Literário proporcionou uma mudança radical de comportamento diz respeito ao envolvimento de Kleiton com o colega que compartilhou com ele a apresentação no evento de 2016.

Uma coisa que mais me interessou, assim, foi que eu e o Vilson não éramos amigos. $\mathrm{Na}$ verdade a gente era inimigo. Brigava o tempo inteiro. $\mathrm{E}$ eu acho que a professora fez isso mesmo de propósito, pra gente se aproximar mais, porque era só eu que faria a encenação (Kleiton fez o papel do escritor Manoel de Barros). Daí ela falou assim: o Vilson vai fazer com você (Vilson interpretou o pai do Manoel de Barros). Eu já pensei: não vai dar certo. Aí ela falou que ia valer nota, dois pontos. Então, ou vocês fazem ou é zero. Daí a gente foi conversando, foi tentando, daí a gente fez amizade, acabou virando amigo. Nunca mais brigamos. (Kleiton).

A forma como a professora Priscila mediou essa situação revela sua atenção também com relação a outros aspectos que não apenas didáticos. Em nossa conversa sobre o contexto dessa decisão, ela confirmou que tinha receio de que aquela parceria talvez não desse certo, contudo tinha expectativa de que a convivência entre os alunos acabasse por resolver a questão da inimizade, o que acabou se concretizando.

Observamos que diferentes formas de avaliação fazem parte de todo o processo que envolve o Sarau Literário. Há pontuação para as equipes de trabalho na fase de organização do evento, há pontuação individual para a participação dos alunos e há ainda a atribuição de nota, de zero a dez, para o desempenho de cada um nas atividades. $\mathrm{O}$ desempenho aqui se refere ao comportamento, à participação e ao esforço individual no enfrentamento dos desafios. Se analisarmos as formas de as professoras avaliarem os alunos de maneira isolada, podemos considerar que se constituem, exclusivamente, em mecanismos de controle verticais. No entanto, os dados apontaram que os efeitos provocados nos alunos são favoráveis à aproximação deles com a literatura, contribuindo para a formação do leitor. Depreendemos desse cenário pelo menos dois aspectos a serem analisados. A escola é construída com base na avaliação - boletim, histórico escolar, códigos de disciplina. Por isso, parece que não é possível funcionar de forma diferente. Mas há outra questão a se considerar. Quando os alunos têm clareza do que é esperado deles, quando são informados a respeito dos seus erros e acertos e dos pontos que precisam corrigir, criam-se novas condições de manterem uma aproximação mais estreita com os 
objetos de conhecimento, ampliando as possibilidades de tomada de consciência daquilo que está inadequado, ressignificando a própria avaliação.

Faz a gente refletir sobre não fazer a coisa errada, que tem o momento a hora certa pra fazer as coisas, fazer o que deve. (Kleiton).

Inferimos que as experiências vivenciadas pelos alunos no Projeto Sarau Literário se caracterizam como um momento rico de aproximação com a leitura literária. A proposição de diversas atividades viabilizando formas de contato dos alunos com o universo literário concretizou experiências importantes, que, aliadas à mediação pedagógica, contribuíram para a formação do leitor.

No entanto, constatamos que todas as práticas referentes ao projeto - organização, implantação, ensaios, execução - estão centradas em uma única pessoa. Não há indícios de envolvimento coletivo que revelem um equilíbrio de forças atuando de forma partilhada. Há colaboração de um ou outro professor. As ideias estão concentradas na professora Priscila e tudo passa pela sua anuência. A gestão entende assim, os outros professores entendem assim e até a própria professora organizadora do Projeto acaba assumindo isso. Desta forma, a estrutura de apoio revela-se fragilizada, uma vez que a base sobre a qual o projeto se sustenta não possui um contexto de força coletiva.

Os resultados apontaram para uma fragilidade em relação ao envolvimento coletivo na organização do Sarau Literário. Há, por um lado, a esperança da professora Priscila em relação ao apoio dos seus pares na realização do projeto e, por outro, as disputas sobre quem seria o "dono" dele.

Diniz-Pereira (2015, p. 128) nos ajuda a refletir sobre essas tensões ressaltando que "[...] o individualismo tem sido historicamente construído como uma das características mais marcantes e mais resistentes da identidade docente”. Destaca ainda que (2015, p. 129):

[...] o isolamento mútuo dos professores, os dilemas do ensino baseado em metas e na avaliação de resultados, a concepção limitada de formação continuada, as condições de trabalho que produzem uma síndrome do mais-do-mesmo entre os professores - participam do complexo processo de produção dessa subcultura ocupacional que parece se reproduzir muito fortemente no magistério. 
A subcultura do individualismo parece ser a base sobre a qual a docência está apoiada. O Projeto Sarau Literário sofre uma ameaça constante à sua sobrevivência - a resistência de parte do corpo docente em participar. Nessa luta de forças quem perde são os alunos, que deixam de participar, se seus professores não participam.

\section{CONSIDERAÇÕES Finais}

O Projeto Sarau Literário envolve os alunos de forma lúdica, aproxima-os de um elemento cultural relevante - a literatura - e tem potencial para auxiliar na formação de leitores literários, além de colaborar para a transformação pessoal dos alunos participantes. Pode ser fortalecido se assumido coletivamente, como um projeto da escola.

Reafirma-se a ideia de que a mediação pedagógica é fundamental para a formação do leitor. As atividades do Projeto Sarau Literário - planejamento, preparação e envolvimento dos alunos com as diversas manifestações estéticas relacionadas com a literatura - são mediadas por sistemas simbólicos, revelando a importância das relações sociais nesse processo.

\section{REFERÊNCIAS}

BRITO, M. L. N. A representação da literatura no Ensino Médio: estudo de caso no Colégio de Aplicação CAP/COLUNI, em Viçosa - MG. 2012. 138 f. Dissertação (Mestrado em Letras) Universidade Federal de Viçosa, Viçosa, 2012.

CHARTIER, R. Práticas da Leitura. Trad. Cristiane Nascimento. São Paulo: Estação Liberdade, 2011. CLOT, Y. A interfuncionalidade dos afetos, das emoções e dos sentimentos: o poder de ser afetado e o poder de agir. In: BANKS-LEITE, L.; SMOLKA, A. L. B.; ANJOS, D. D. (Org.). Diálogos na perspectiva histórico-cultural: interlocuções com a clínica da atividade. Campinas, SP: Mercado de Letras, 2016.

DINIZ-PEREIRA, J. E. A construção social do individualismo na profissão docente: como transcender as fronteiras tradicionais da identidade dos professores? Revista de Educação PUC-Campinas, [S.1.], v. 20, n. 2, p. 127-142, nov. 2015. Doi: <https://doi.org/10.24220/2318o870v2on2a2993>.

LEAHY-DIOS, C. Educação Literária como Metáfora Social - Desvios e rumos. São Paulo: Martins Fontes, 2004.

MAGNANI, M. R. M. Leitura, Literatura e Escola - Sobre a Formação do Gosto. São Paulo: Martins Fontes, 2001.

ROCCO, M. T. F. Literatura/Ensino: uma problemática. São Paulo: Editora Ática, 1992.

SILVA, L. M. Memórias de leitura: a constituição do leitor escolar. 2005. 248 f. Dissertação (Mestrado em Educação) - Universidade Estadual de Campinas, Campinas, SP, 2005. 
SOARES, M. Letramento: um tema em três gêneros. Belo Horizonte: Autêntica Editora, 2016.

SOUZA, J. S. Z. O papel da família na constituição do leitor. In: LEITE, S. A. S. (Org.). Afetividade e práticas pedagógicas. São Paulo: Casa do psicólogo, 2011.

TASSONI, E. C. M.; LEITE, S. A. S. Um estudo sobre emoções e sentimentos na aprendizagem escolar. Comunicações, Piracicaba, ano 18, n. 2, p. 79-91, jul./dez. 2011.

TOSTA, C. G. Vigotski e o desenvolvimento das Funções Psicológicas Superiores. Perspectivas em Psicologia, v. 16, n. 1, p. 57-67, jan./jun. 2012. Disponível em: <http://www.seer.ufu.br/index.php/ perspectivasempsicologia/article/view/27548>. Acesso em: 02 fev. 2017.

VYGOTSKI, L. A formação social da mente. Trad. José Cipolla Neto, Luís Silveira Menna Afeche e Solange Castro Afeche. São Paulo: Martins Fontes, 1989.

\section{SOBRE OS AUTORES}

João Marcos Pulz Araújo é graduado em Publicidade e Propaganda (Universidade Metodista de Piracicaba), tem Pós-Graduação em Comunicação (Escola Superior de Propaganda e Marketing) e Mestrado em Educação (Pontifícia Universidade Católica de Campinas). Tem experiência nas áreas de criação literária e redação publicitária, com ênfase nos processos de escrita criativa.

E-mail: bulzara@gmail.com.

Elvira Cristina Martins Tassoni é graduada em Pedagogia (Pontifícia Universidade Católica de Campinas), tem Mestrado e Doutorado em Educação (Universidade Estadual de Campinas). É professora/pesquisadora do Programa de PósGraduação em Educação da Pontifícia Universidade Católica de Campinas. Tem experiência na área de Formação de Professores e Práticas Pedagógicas, com pesquisa nos seguintes temas: afetividade e as condições de ensino e aprendizagem; alfabetização e letramento; mediação pedagógica; educação básica.

https://orcid.org/oooo-0002-8968-3981.

E-mail: cristinatassoni@puc-campinas.edu.br.

Recebido em 18 de janeiro de 2018 e aprovado em 22 de março de 2018. 